\title{
SPECTROSCOPIC CHARACTERIZATION OF INTERMEDIATES IN THE IRON CATALYZED ACTIVATION OF ALKANES
}

\author{
Final Technical Report \\ For Period April 1, 1993 to July 31, 2006 \\ Edward M. Eyring \\ University of Utah \\ Salt Lake City, UT 84112-0850 \\ May 28, 2008 \\ Prepared for \\ THE U.S. DEPARTMENT OF ENERGY \\ AGREEMENT NO. DE-FG03-93ER14340
}


Spectroscopic Characterization of Intermediates in the Iron Catalyzed Activation of Alkanes

\section{Final Report Abstract}

The present report begins with a brief survey of recent hypervalent iron chemistry and mentions two previously reported ferrate papers funded by the DOE/BES grant. The focus is then shifted to the seven publications acknowledging support of the grant that have not been reported since the last Progress Report, DOE/ER/14340-9, was prepared. These papers deal with: (a) the successful use of an ATR element in a stopped-flow infrared spectrometer, (b) the rationalization of a depolarization of $\mathrm{LiClO}_{4}$ solution in polyethylene oxide high polymer, (c) an analysis of several coupled ultrasonic relaxations observed in solutions of pentoses undergoing isomerization, (d) the combination of ultrasonic absorption and Raman scattering measurements to elucidate zinc thiocyanate solutions in water, (e) the use of NMR to determine stability constants when $\mathrm{LiClO}_{4}: 12$-crown-4 is dissolved in acetonitrile and in methanol, (f) the possible existence of triple ions in low permittivity solutions, and $(\mathrm{g})$ the properties of a high surface area ceria aerogel. Collectively, these papers illustrate advantages of bringing several modern experimental techniques to bear on complex chemical systems.

\section{NOTICE}

This report was prepared as an account of work sponsored by the United States Government. Neither the United States nor the Department of Energy, nor any of their contractors, subcontractors, or their employees makes any warranty, expressed or implied, or assumes any legal liability or responsibility for the accuracy, completeness, or usefulness of any information, apparatus, product or process disclosed or represents that its use would not infringe privately-owned rights. 
The redox chemistry of transition metal elements that have several oxidation states will always be of great interest to biochemists and inorganic chemists. A current example is the possible use of the equilibrium between the solid copper(I) oxide and copper(II) oxide as an oxygen carrier in chemical looping combustion ${ }^{1}$ which shows promise for facilitating sequestration of carbon dioxide at coal-fired power plants.

The rich chemistry of polyvalent iron is well reported in the current scientific literature. Representative examples include a literature review by $\mathrm{Groves}^{2}$ entitled "High-Valent Iron in Chemical and Biological Oxidations," the description of "An Octahedral Coordination Complex of Iron(VI)" authored by Berry and coworkers, ${ }^{3}$ and papers by Licht and coworkers that promote the use of iron(VI) in future batteries ${ }^{4}$ and in the purification and remediation of municipal water supplies. ${ }^{5}$

With DOE/BES support, students in the Eyring lab at the University of Utah undertook stopped-flow spectrophototometric kinetic studies of aqueous iron(VI) systems. The first of these studies culminated in a published paper ${ }^{6}$ describing the oxidation of aqueous aniline by iron(VI). A spin trap, POBN, was used in these EPR experiments to establish that the oxidation of aniline by iron(VI) involves the formation of an aniline free radical. In a similar study ${ }^{7}$ of iron(VI) oxidation of aqueous phenol, a comparison of reaction rates in water and in $\mathrm{D}_{2} \mathrm{O}$ strongly suggested that a hydrogen bond forms in the transition state. The similarity of the results of these studies suggested that the application of a broader range of experimental tools to reaction rate studies in condensed phases would be scientifically more fruitful than a string of stopped-flow rate studies of iron(VI) oxidizing different organic molecules in aqueous solution. The seven papers ${ }^{8-14}$ acknowledging DOE/BES support that resulted from this broad attack are reported below in chronological order by their technical Abstracts. 


\title{
Stopped-Flow FT-IR Spectroscopy of Aqueous Solutions Using Attenuated Total Reflectance
}

\author{
Brian C. Dunn, Jonathan R. Marda, and Edward M. Eyring \\ Department of Chemistry, University of Utah, Salt Lake City, Utah 84112
}

APPLIED SPECTROSCOPY 2002, $\underline{56}, 751-755$

\begin{abstract}
An apparatus for the study of solution phase kinetics using FT-IR spectroscopy has been developed. The observation chamber consists of an integrated tangential mixer-flow cell and a ZnSe element permitting attenuated total reflectance (ATR) measurements. The short optical pathlength afforded by ATR allows midIR observation of chemical reactions in aqueous solution, including the spectral region near the water bending vibration $\left(1640 \mathrm{~cm}^{-1}\right)$. High hydraulic back-pressures required to force solution rapidly through a thin layer flow cell are not necessary with the ATR flow cell because the optical pathlength and the flow cross-section have been decoupled, allowing for a relatively large flow chamber when compared with instruments incorporating a transmission flow cell. Overall system performance has been evaluated using the hydrolysis of methylchloroacetate as a test reaction. The feasibility of observing reactions with initial half-lives of approximately $250 \mathrm{~ms}$ is demonstrated. The system is very robust, with little risk of damaging the optics during routine maintenance.
\end{abstract}

\section{Microwave Dielectric Relaxation, Electrical Conductance and Ultrasonic Relaxation of $\mathrm{LiCIO}_{4}$ in Polyethylene Oxide Dimethyl Ether-500 (PEO-500)}

\author{
Sergio Petrucci ${ }^{\mathrm{a}}$ and Edward M. Eyring ${ }^{*} \mathrm{~b}$ \\ a Polytechnic University, Farmingdale, NY 11735. USA \\ b Department of Chemistry, University of Utah, Salt Lake City, Utah 84112, USA
}

PHYS. CHEM. CHEM. PHYS. 2002, 4, 6043-6046

\begin{abstract}
The relevance of establishing the structure of electrolyte solutions of low dielectric permittivity is briefly recalled. Microwave complex dielectric permittivities $\varepsilon^{*}=\varepsilon^{\prime}-J \varepsilon^{\prime \prime}$ in the frequency range $\sim 1$ to $130 \mathrm{GHz}$ for $\mathrm{LiClO}_{4}$ dissolved in poly(ethylene oxide)dimethvl ether of average molar mass 500 (PEO-500), in the concentration range 0.40 to $1 \mathrm{~mol} \mathrm{dm}$, at $25^{\circ} \mathrm{C}$, are reported. The data are interpreted by a Cole-Davidson distribution function. Molar electrical conductance for the same system, in the concentration range $7 \times 10^{-4}$ to $\sim 1 \mathrm{~mol} \mathrm{dm}{ }^{-3}$, shows a minimum and a maximum as a function of the electrolyte concentration. The data, in the diluted range $\left(\leq 0.017 \mathrm{~mol} / \mathrm{dm}^{3}\right)$ are interpreted by the Fuoss-Onsager equation, in terms of free ions and ionpair-species. Ultrasonic relaxation spectra in the frequency range 1 to $300 \mathrm{MHz}$ and concentration range 0.1 to $\sim 0.4 \mathrm{~mol} \mathrm{dm}^{-3}$, are interpreted by the ion-pair dimerization equilibrium $2 \mathrm{LiClO}_{4} \leftrightarrow\left(\mathrm{LiClO}_{4}\right)_{2}$, the dimer being an apolar antiparallel species $\left(\begin{array}{l}\mathrm{Li}^{+} \mathrm{ClO}_{4}{ }^{-} \\ \mathrm{ClO}_{4}{ }^{-} \mathrm{Li}^{+}\end{array}\right)$, thus rationalizing the depolarization of the solution with the consequent appearance of a maximum in the dielectric permittivity of the solution at high electrolyte concentration. A parallel with previous work on $\mathrm{LiPF}_{6}$ dissolved in the same solvent is drawn.
\end{abstract}




\title{
Molecular Dynamics of the Interaction of Some Alkaline-Earth Cations with Some Pentoses Undergoing $4 \mathrm{C}_{1} \rightleftharpoons 1 \mathrm{C}_{4}$ Isomerization
}

\author{
Sergio Petrucci*,t and Edward M. Eyring ${ }^{1}$ \\ Polytechnic University, Long Island Center, Farmingdale, New York 11735, \\ and Department of Chemistry, University of Utah, Salt Lake City, Utah 84112
}

J. PHYS. CHEM. A 2002, 106, 8859-8863

\begin{abstract}
Ultrasonic relaxation spectra in the frequency range 0.08-400 $\mathrm{MHz}$ of the ions $\mathrm{Ca}^{2+}$ or $\mathrm{Ba}^{2+}$, interacting with the pentoses D-(-)-ribose, D-(-)-1yxose, and D-(-)-arabinose at concentrations of $0.5 \mathrm{M}$ and molar ratio $\left(\right.$ pentose $/$ metal $\left.^{2+}\right)=1$ at $25^{\circ} \mathrm{C}$, are reported. For $\mathrm{Ca}^{2+}$ or $\mathrm{Ba}^{2+}$ with $\mathrm{D}-(-)$-ribose ultrasonic relaxation spectra at various concentrations up to $c=0.7 \mathrm{~mol} / \mathrm{dm}^{3}$ at $25^{\circ} \mathrm{C}$ are also reported. The ultrasonic spectra can be interpreted by the sum of three Debye relaxation processes. The one at the lowest relaxation frequency $(\sim 0.07-0.25 \mathrm{MHz})$ is ascribed to the $4 \mathrm{C}_{1} \rightleftharpoons 1 \mathrm{C}_{4}$ isomerization of the carbohydrates. The relaxation process at intermediate frequency $\left(\sim 10-12 \mathrm{MHz}\right.$ for $\mathrm{Ca}^{2+}$ or $50-60 \mathrm{MHz}$ for $\left.\mathrm{Ba}^{2+}\right)$ is interpreted as due to the partial desolvation of the cations by the carbohydrate. The "fast" relaxation process at $120-160 \mathrm{MHz}$ is attributed to the diffusioncontrolled approach and initial desolvation of the cation and carbohydrate. The two faster processes are interpreted according to the multistep Eigen-Tamm complexation mechanism: $\mathrm{M}^{2+}+$ carbohydrate $\rightleftharpoons$ $\left(k_{1} / k_{-1}\right) \mathrm{M}^{2+} \ldots$ carbohydrate $\rightleftharpoons\left(k_{2} / k_{-2}\right) \mathrm{M}^{2+}$ carbohydrate. For the nonspecialist reader, the $4 \mathrm{C}_{1} \rightleftharpoons 1 \mathrm{C}_{4}$ symbolism refers to the process illustrated below, where the numbers identify the upper or lower position of the carbon atoms 4 or 1 of the carbohydrate ring with respect to the plane passing through the carbon atoms 2,3 , and 5 and the oxygen atom of the ring.
\end{abstract}

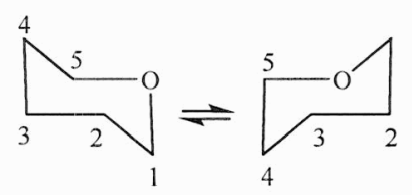




\title{
Ultrasonic and Raman Scattering Spectroscopy of Zinc Thiocyanate Complexes in Water at $25^{\circ} \mathrm{C}$ : Kinetics of Complex Formation Determined by Multivariate Analysis
}

\author{
Rory H. Uibel, ${ }^{1}$ Emily C. Heider, ${ }^{1}$ Jennifer L. Gasser, ${ }^{1}$ \\ Joel M. Harris, ${ }^{1}{ }^{*}$ Edward M. Eyring, ${ }^{1}$ and Sergio Petrucci ${ }^{2}$ \\ 'University of Utah, Department of Chemistry, 315 S. 1400 East, Salt Lake City, Utah 84112; \\ e-mail:harisj@chem.uteh.edu andevring@chem.atah.edu. \\ ${ }^{2}$ Polytechnic University, Long Island Graduate Center, Melville Corporate Center, \\ 105 Maxess Road, Melville, New York 11747.
}

JOURNAL OF SOLUTION CHEMISTRY 2005, $\underline{34}, 449-514$

\begin{abstract}
Advances have been made recently in broadening the accessible ultrasonic absorption frequency range and improving the detectability of minor species present in solution using Raman spectroscopy. Development of chemometric techniques in these areas needs to keep pace with the improvement of these experimental methods. Refinements in the analysis of ultrasonic and Raman data based on multivariable least squares and factor analysis, respectively, are examined to investigate the kinetics of zinc thiocyanate complex formation in water. Analysis of ultrasonic absorption relaxation spectra verified that the observed process in aqueous $\mathrm{Zn}(\mathrm{SCN})_{2}$ involves substitution of water from the first coordination shell of $\mathrm{Zn}^{2+}$. Use of a multivariable least-squares error surface is described that enhances the reliability of assigned frequencies of ultrasonic absorption maxima. Factor analysis of Raman scattering data provided direct evidence that at least four complex species, such $\mathrm{Zn}(\mathrm{SCN})^{+}$and $\mathrm{Zn}(\mathrm{SCN})_{2}$, are simultaneously present in the aqueous zinc thiocyanate solutions.
\end{abstract}

\section{Stability Constants: Comparative Study Of Fitting Methods. Determination Of Second-Order Complexation Constants by ${ }^{23} \mathrm{Na}$ and ${ }^{7} \mathrm{Li}$ NMR Chemical Shift Titration}

\author{
Marilyn C. Masiker, Charles L. Mayne and Edward M. Eyring* \\ Department of Chemistry, University of Utah, Salt Lake City, Utah, USA
}

MAGNETIC RESONANCE IN CHEMISTRY 2006, 44: 220-229

\begin{abstract}
NMR chemical shift titration has been widely used as a method for the determination of stability constants. Systems involving metal-ligand complexation have been investigated using a number of methodologies. There are significant differences in the values reported for stability constants obtained by different experimental methods, such as calorimetry and ion selective electrode (ISE) titrations; nor has NMR chemical shift titration always yielded consistent results. Different researchers have obtained different results for the same system with results differing by as much as an order of magnitude. The chemical shift data are generally plotted against the concentration ratio of the metal and ligand for a set of solutions. A nonlinear least squares fitting method using an analytical solution of the cubic equation for the equilibrium concentration of the free ligand is used in this study and compared with methods used in the literature. Second-order association constants for the $\mathrm{LiC1O}_{4}: 12$-crown-4 system in acetonitrile and the $\mathrm{NaC}_{1} \mathrm{O}_{4}: 12$-crown-4 system in methanol are reported. Formation of both $1: 1$ and $1: 2$ metal-ligand complexes are considered. The $\mathrm{LiC}_{1} \mathrm{O}_{4}: 12$-crown- 4 acetonitrile system had been investigated previously by NMR titration but only 1:1 complexation was considered in that study. This study provides convincing evidence that both $1: 1$ and $1: 2$ complexes are important, at least, in the lithium system. A Monte Carlo investigation of the propagation of errors from the chemical shifts to the stability constants shows that the choice of data analysis methods may, in part, contribute to discrepancies and that the nonlinear nature of the model can dramatically affect the error limits on the stability constants.
\end{abstract}




\title{
The possible presence of triple ions in electrolyte solutions of low dielectric permittivity.
}

\author{
Sergio Petrucci ${ }^{\mathrm{a}}$, Marilyn C. Masiker ${ }^{b}$, Edward M. Eyring ${ }^{\mathrm{b}}$ \\ ${ }^{a}$ Polytechnic University, Long Island Campus, Melville, NY \\ ${ }^{b}$ Department of Chemistry, University of Utah, Salt Lake City, UT 84112
}

JOURNAL OF SOLUTION CHEMISTRY, in press (projected publication, June 2008)

\begin{abstract}
The cause of the appearance of a minimum in the electrical conductivity in many electrolyte solutions of low dielectric permittivity with increasing electrolyte concentration is reviewed. Tentative explanations include formation of triple ions or alternatively the electrical polarization of the solutions due to the addition of electrolyte as ion pairs. Theoretical models for linear triple ions and apolar dimers are examined. Experimental evidence favors the polarization hypothesis over triple ions; the maximum in the dielectric permittivity with concentration of electrolyte is consistent with an equilibrium between ion pairs $\mathrm{AB}$ and dimers $\mathrm{A}_{2} \mathrm{~B}_{2}$ at higher concentrations.
\end{abstract}

\section{A Simple Synthesis of Catalytically Active, High Surface Area Ceria Aerogels}

\author{
Jennifer L. Gasser-Ramireza , Brian C. Dunn ${ }^{\mathrm{a}}$, Daniel W. Ramirez ${ }^{\mathrm{a}}$, Eric P. Fillerup ${ }^{\mathrm{a}}$, Gregory \\ C. Turpin ${ }^{\mathrm{a}}$, Yifan Shi ${ }^{\mathrm{a}}$, Richard D. Ernst ${ }^{\mathrm{a}}$, Ronald J. Pugmire ${ }^{\mathrm{a}}$, Edward M. Eyring ${ }^{\mathrm{a},}$, Katherine \\ A. Pettigrew ${ }^{\mathrm{b}}$, Debra R. Rolison ${ }^{\mathrm{b}}$, Joel M. Harris ${ }^{\mathrm{a},{ }^{*}}$ \\ "Department of Chemistry, University of Utah, Salt Lake City, Utah 84112, USA \\ ${ }^{b}$ U.S. Naval Research Laboratory, Washington, DC 20375, USA \\ JOURNAL OF NON-CRYSTALLINE SOLIDS, \\ submitted for publication April 2, 2008
}

\begin{abstract}
A simple synthetic route for preparing high surface area, structurally stable ceria aerogels is presented. Ceria aerogels were doped with $1 \%$ palladium: a water-gas shift (WGS) active metal. A reduced Pd/ceria aerogel and an as-prepared $\mathrm{Pd} /$ ceria aerogel are compared to determine the effect of pretreatment conditions on WGS activity. The BET surface area of the as-prepared ceria aerogel was $345 \mathrm{~m}^{2} / \mathrm{g}$. CO chemisorption data and high-resolution TEM images indicate that the particle size of palladium on the reduced $\mathrm{Pd} /$ ceria sample was approximately $15 \mathrm{~nm}$. X-ray photoelectron spectroscopy (XPS) data establish that the fraction of $\mathrm{Ce}^{3+}$ from $\mathrm{Ce}_{2} \mathrm{O}_{3}$ was approximately the same for both reduced and as-prepared samples. XPS data also indicate that approximately $44 \%$ of the palladium on the reduced $\mathrm{Pd} /$ ceria sample was converted to the metallic form. Each catalyst was tested for WGS activity. The reduced $\mathrm{Pd} /$ Ceria sample exhibited the greatest WGS activity as compared with the other samples used in this study.
\end{abstract}




\section{Human Resources}

The personnel working on papers 6-14 listed in alphabetical order are:

(1) Brian Dunn, Postdoctoral Fellow at the University of Utah; now a permanent staff member at Conoco/Phillips, Bartlesville, OK

(2) Richard Ernst, Professor of Chemistry at the University of Utah

(3) Edward Eyring, Professor of Chemistry at the University of Utah

(4) Eric Fillerup, Undergraduate Chemistry major at the University of Utah; now in the Ph.D. program at Pennsylvania State University

(5) Jennifer Gasser, Graduate student originally in Eyring lab; now working in Joel Harris' $1 \mathrm{ab}$

(6) Joel Harris, Distinguished Professor of Chemistry at the University of Utah

(7) Emily Heider, Graduate student in Joel Harris' lab

(8) Hua Huang, Postdoctoral Fellow at the University of Utah; now a proteomics mass spectroscopist at a company in Irvine, CA

(9) Christopher Lloyd, Graduate student at the University of Utah; now employed by a biotech company in Tuscon, AZ

(10) Jon Marda, Undergraduate student at the University of Utah; went into the U.S. Navy

(11) Marilyn Masiker, Postdoctoral Fellow at the University of Utah who earned her Ph.D. degree in the E. Eyring lab

(12) Charles Mayne, Ph.D. chemist on the staff of the NMR Center at the University of Utah

(13) Sergio Petrucci, Chemistry Professor retired from Polytechnic University, NY

(14) Katherine Pettigrew, Postdoctoral scientist at the U.S. Naval Research Lab, Washington, $\mathrm{DC}$

(15) Ronald Pugmire, Professor of Chemical Engineering and Associate Vice President for Research at the University of Utah

(16) Debra Rolison, Lab Director at the U.S. Navel Research Lab, Washington, DC

(17) Yifan Shi, Graduate student at the University of Utah working in the Richard Ernst labs

(18) David Sommerfeld, Graduate student at the University of Utah and subsequently a Postdoctoral Fellow with Sherry Rowland, University of California, Irvine Greg Turpin, Graduate Student at the University of Utah working in the Ernst labs Rory "Ziggy" Uibel, recent Ph.D. graduate from the Joel Harris research group at the University of Utah; now employed by Process Instruments, Inc., Salt Lake City 